undesirable consequences of the rapidly expanding private sector for the public mission of higher education, but public institutions seldom become accountable to the fulfillment of their own public mission. Nonstate institutions require state recognition and legitimacy to operate, enjoy rights and privileges granted by public authority, and benefit from direct and indirect subsidies. The proliferation of new, profitdriven institutions responding to student demand, often with public support, does pose a major challenge to quality assurance in defense of the rights of students. A revisiting of the public mission is in order for all institutional segments and for the higher education system as a whole.

The definition of a public mission for higher education is subject to national and local politics and often becomes a very contentious issue, exacerbated when government support declines. The worldwide increase in income and wealth inequalities has highlighted the tension around fairness and equity in access to higher education, an important dimension of its pubic mission. The failure of massification to significantly reduce the gap between income groups among nations, where mass access is a recent phenomenon, is well documented. In many middle-income countries governments are allocating a disproportionate share of scarce resources to support public institutions with higher per-student costs, a strategy often justified in terms of the limited capacity of the private sector, in the production of basic research and advanced training. Fulfillment of the public mission requires greater transparency in the use of public funds, to make sure that benefits are not disproportionally enjoyed by better-off students and that higher education in all its functions serves the society at large.

There is also a universal dimension to the public mission of higher education, one that transcends the national, regional, and local settings but needs to be protected and nurtured by institutions and governments alike. Knowledge production, a centerpiece of that dimension, takes place on a global scale and crosses political boundaries, increasingly so thanks to the technological revolution in communications. Higher education institutions are key agents in the global production of knowledge, through basic scientific and humanistic research, and thus they are accountable to an evolving set of norms and values that drive and regulate knowledge production, its public, and increasingly collaborative nature. Although internationalization has become a buzzword among higher education institutions, its publicmission dimension - the safeguard and promotion of collaborative, reciprocal, and respectful relations in knowledge production and distribution across national boundariesneeds to be recognized more explicitly and implemented more carefully by institutions and public agencies.

\section{Equity Remains a Most-Im- portant Challenge, Facing Global Higher Education}

\section{Roberta Malee Bassett}

Roberta Malee Bassett is senior education specialist, Global Practice: Education at the World Bank.E-mail: rbassett@worldbank.org.

The intersection of technology and higher education has been driving the headlines on "the future" of higher education, for the better part of the past two decades. Indeed, since the industrial revolution, popular culture has often equated technology with the future. But, education-for all its adaptations to the world around it-is a human endeavor, and supporting and promoting the "humanity" of higher education will remain the key challenge for higher education stakeholders in perpetuity.

What is the humanity of higher education? Stakeholders including future, current, and former students; families; academic and administrative staff; employers; policymakers? In fact, higher education reaches into the lives of every person on earth - through research, technology, teacher training, and others. But, the ability to directly contribute to and benefit from higher education remains largely limited to the global elite. Equitable access to the full benefits of higher education will, therefore, remain the single, mostimportant challenge facing global higher education for the foreseeable future.

Supporting the equity of opportunity to seek the benefits, afforded by tertiary education, is economically and socially important in light of the documented evidence on the public and private benefits of attaining a college degree. Individual, private benefits include improved health outcomes, increased earning potential and even greater life satisfaction and expectancy, while the public, societal benefits include lower unemployment rates, increased tax revenues, greater civic and volunteer participation, and lessened dependency on social services. Furthermore, expanded access to tertiary education among members of disadvantaged communities extends these public benefits into communities, most in need of supportive interventions.

In spite of expanded access worldwide, however, higher education-especially the most prestigious university sector-generally remains inaccessible, with the majority of enrolled students coming from wealthier segments of society. Although relatively few countries and institutions systematically collect data on the socioeconomic origin of students, where national statistics and household survey data are available, the pattern of inequality is clear. In Chile, 
for instance, the higher education level-enrollment rate for the wealthiest quintile is almost four times higher than the rate for the poorest. In Argentina, the enrollment rate of the wealthiest is five times higher than the rate for the poorest, and in Mexico the rate is I8 times higher than that of the poorest. In the francophone countries of sub-Saharan Africa, the children of the richest quintile account for 80 percent of higher education enrollment, while those from the poorest 40 percent of the population group represent only 2 percent of the student population.

Enrollments are expanding in gross numbers across the globe, no question, but this massification has happened within privileged groups, not across all socioeconomic groups. Distributing the well-documented and important benefits of higher education to all strata of society will, therefore, remain the most-important challenge for higher education in the decades to come.

\section{The Challenge of Effective Teaching}

\section{ANDRÉs BERnASCON I}

Andrés Bernasconi is professor at the Pontificia Universidad Católica de Chile.E-mail: abernasconi@uc.cl.

For a millennium now, higher education has fostered scholarship and educated people in advanced knowledge. To these core functions others have been added over time, varying in their definition and urgency-such as service to the mission of a church, training civil servants, cementing a national identity, pulling the train of development, spearheading technological innovation, etc. However, teaching and discovery have remained as the essence of the institution we typically associate with the idea of the university and similar centers of higher learning.

Yet, with the reinvention of the university in modern times, research has taken precedence over education as the defining feature of excellence and distinction in this field. True, in the I9th century Humboldtian model, education was to be carried upon the shoulders of the scientific endeavor. Yet, in the age of massification, such virtuous interaction between the activity of research and the environment for learning takes place almost exclusively in the ambit of doctoral training.
Moreover, as academic drift increasingly blurs the research-based definitional line that sets apart universities from nonuniversity tertiary institutions, we see colleges and universities of applied sciences (fachhochschulen) - as well as other institutions that are supposed to have a predominant or exclusive orientation to professional and technical education - veer away from that identity to embrace a research mission, at least in ambition.

Institutional prestige and the personal reputation of faculty are pegged solely to research accomplishments. This association is reinforced today by global rankings, thus the teaching function remains secondary in institutional and professional rewards, attention from the leadership, development of capabilities among the practitioners, and seemingly, in results as well.

This subordination of teaching to research is no longer tenable. For one thing, the overwhelming majority of institutions of higher education around the world carry out no research. For them, the only achievable excellence is of teaching and learning. Next, the minuscule proportion of the world's students who attend the most selective research universities worldwide are generally already quite capable of learning and intellectual development, regardless of the teaching talent of their professors. For the colossal majority of students not attending elite institutions, however, a capable cadre of teachers makes the difference between students dropping out (or graduating, but with minimal learning) versus real mastery of the discipline or the profession that the degree is meant to represent. Moreover, the patience of politicians, with the results achieved by institutions of higher education, seems to be at an all-time low, to judge from the general lack-of-confidence zeitgeist of public policy in the last 30 years, from Britain to Japan to Mexico. Also, this frustration comes not from lackluster research performance, but from poor or unknown effects of higher education over manpower development and productivity.

The time will come when teaching will be open to the same kind of exacting peer scrutiny and judgment as research. Student evaluations will be complemented with expert analysis and feedback over video recordings of classroom, seminar, or laboratory practice. Rewards and recognition will be bestowed upon those who excel in expanding the reach of the minds of their students. 